\title{
Erratum: "Atomic Structure of MBE-Grown GaAs Nanowhiskers" [Phys. Solid State 47, 2213 (2005)]
}

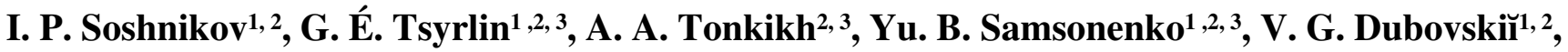
V. M. Ustinov ${ }^{1,2}$, O. M. Gorbenko ${ }^{3}$, D. Litvinov ${ }^{4}$, and D. Gerthsen ${ }^{4}$

${ }^{1}$ St. Petersburg Physicotechnical Science \& Education Center, Russian Academy of Sciences, St. Petersburg, 195220 Russia

${ }^{2}$ Ioffe Physicotechnical Institute, Russian Academy of Sciences, Politekhnicheskaya ul. 26, St. Petersburg, 194021 Russia e-mail:ipsosh@beam.ioffe.rssi.ru

${ }^{3}$ Institute of Analytical Instrument Making, Rizhskiü pr. 26, Russian Academy of Sciences, St. Petersburg, 198103 Russia ${ }^{4}$ Technical University of Karlsruhe, Karlsruhe, D-76128 Germany

Submitted December 14, 2005; accepted for publication December 14, 2005

PACS numbers: 99.10.Cd

DOI: $10.1134 / \mathrm{S} 1063783406020375$

The surname of the fifth author should read V. G. Dubrovsky. 